RASĀYAN J. Chem.

Vol. 13 | No. 3 |1834-1841| July - September | 2020

ISSN: 0974-1496 | e-ISSN: 0976-0083 | CODEN: RJCABP

RJC

http://www.rasayanjournal.com

http://www.rasayanjournal.co.in

\title{
STRUCTURAL AND THERMAL CHARACTERIZATION OF SYNTHESIZED POLYESTER RESIN BASED ON A NEW LINSEED VARIETY (SHUATS-ALSI 2)
}

\author{
A. Chowdhury ${ }^{1, *}$, S. K. Singh ${ }^{1}$, S. Marker ${ }^{2}$ and P. Anthony ${ }^{1}$ \\ ${ }^{1}$ Department of Chemistry, Faculty of Science, Sam Higginbottom University of Agriculture, \\ Technology \& Sciences, Prayagraj-211007, (Uttar Pradesh) India. \\ ${ }^{2}$ Department of Genetics and Plant Breeding, Naini Agricultural Institute, Sam Higginbottom \\ University of Agriculture, Technology \& Sciences, Prayagraj-211007, (Uttar Pradesh) India. \\ *E-mail: abhishek.chowdhury2089@gmail.com
}

\begin{abstract}
In recent times, industrial as well as academic researchers are trying to develop bio-based polyesters as a better alternative for petroleum-based ones. Their main goal is to synthesize materials that can lead to biodegradation with comparable performance. Plant oil serves as an eco-friendly, renewable natural resource and exhibits some remarkable properties. They are readily available in nature, sustainable and inexpensive. Vegetable oil-based polyesters are almost equally applicable as petroleum-based polyester. Vegetable oil-modified polyesters have been studied over a long period. Continuous researches are undertaken to utilize the commonly used vegetable oils and new oils are also explored for their possibility to be used in producing polymers. In the present work, unsaturated polyester resin (UPRs) based on new linseed variety (SHUATS-ALSI 2) was synthesized. Structural and thermal properties were studied and compared with commercially available resins. FT-IR and ${ }^{1} \mathrm{H}-\mathrm{NMR}$ spectroscopy was applied to explore the chemical structure of synthesized resin. TGA analysis reveals comparable thermal stability of both resins i.e. synthesized and commercial. TGA curve was further considered to evaluate Ts and IPDT parameters. Keywords: Vegetable Oil, Linseed Oil, Unsaturated Polyester Resin, Thermal Decomposition, Renewable Resource, Biodegradable Polymers.
\end{abstract}

(C) RASĀYAN. All rights reserved

\section{INTRODUCTION}

Numerous varieties of unsaturated polyesters are known to exist, exhibiting even greatly numbered potential applications, an enlistment of which could exhaust several reams. Industries related to construction, transportation and marines accommodate the major categories of such ubiquitous utilities. ${ }^{1}$ The most attractive property which makes unsaturated polyester resin (UPRs) as one of the essential polymers is their price to property ratio. ${ }^{2}$ Due to the proportional thermo-mechanical and chemical properties, these materials extensively finds applications in coating and composite industries. ${ }^{3}$ Almost 7\% of all oil and gas used worldwide is utilized for synthesizing non-renewable polymeric materials. ${ }^{4}$ Mostly used raw materials in industries of UPRs are generated from petroleum resources such as propylene glycol, maleic anhydride and phthalic anhydride. ${ }^{3}$

However, due to environmental and sustainability issues, a growing concern in our modern society is to replace these fossil fuel-based monomers. In this respect, renewable raw material such as vegetable oil will be a better substitute for synthesizing UPRs. ${ }^{5}$ Due to their biodegradable nature, easy availability and low toxicity it is an interesting renewable source for such synthesis. ${ }^{6}$ Vegetable oils are triglycerides that play a major role in the synthesis of various polymeric structures like linear and cross-linked. ${ }^{7}$ Several studies have been focused on the substitution of such natural materials for synthetic ones. Thermoset resin based on epoxidized linseed oil was developed and further, their thermo-mechanical properties were studied and compared with castor oil and commercial resin-based materials. ${ }^{8}$ Linseed oil-based alkyd resin was utilized in paint formulation. ${ }^{9}$ Glass fiber-reinforced composite based on photosensitive Rasayan J. Chem., 13(3), 1834-1841(2020) http://dx.doi.org/10.31788/ RJC.2020.1335875 
RASĀYAN J. Chem.

Vol. 13 | No. 3 |1834-1841| July - September | 2020

thermoset resin from linseed oil were developed and its mechanical, as well as biodegradable behavior, was compared with natural fiber-based composites. ${ }^{10}$ Chaulmoogra and Alexandrian Laurel seed oil was used to produce polyol through solvent-free glycerolysis technique; its structural and thermal properties were further evaluated. ${ }^{11}$ Thermomechanical properties of UPRs based on soybean and coconut oil were studied $^{3}$. Synthesis of Broccoli seed oil-based polyester was carried out through two steps process: $\mathrm{C}=\mathrm{C}$ was oxidized to produce oxiranes that underwent ring-opening with dicarboxylic acids. ${ }^{12}$ Karanja $^{13}$, Yellow oleander ${ }^{14}$, Jatropha curcas $^{15}$, Nahar ${ }^{16}$ seed oil-based polyester resins were prepared and tested for coating applications. Such contributions of scientists assure vegetable oil-based polymers as a useful material for various applications. Linseed (linumusitatissimum L.) oil is an attractive resource for various industries because of its high unsaturation index which makes its properties superior to other oils. ${ }^{5}$ In the present work, unsaturated polyester resin (UPRs) based on new linseed variety (SHUATS-ALSI 2) was synthesized. Structural and thermal properties were studied and compared with commercially available resins. FT-IR and ${ }^{1} \mathrm{H}-\mathrm{NMR}$ spectroscopy was applied to explore the chemical structure of synthesized resin. TGA analysis reveals comparable thermal stability of both reins i.e. synthesized and commercial. TGA curve was further considered to evaluate Ts and IPDT.

\section{Material and Methods}

\section{EXPERIMENTAL}

SHUATS ALSI-2 is a novel linseed (flax) variety developed at Sam Higginbotttom University of Agriculture, Technology and Sciences, Prayagraj. This variety is well suited to irrigated farm conditions, matures in 123-125 days, is found resistant to powdery mildew and rust with an average yield of 11.10 $\mathrm{q} /$ ha, oil content $37-40 \%$ suitable for cultivation throughout the state of Uttar Pradesh. ${ }^{17}$ The seeds of SHUATS -ALSI 2 were collected from the field of the Department of Genetics \& Plant breeding of Sam Higginbottom University of Agriculture, Technology \& Sciences. (SHUATS), Allahabad (India). Phthalic anhydride (PA) and Hexane was purchased from Merck, India. Adipic Acid (AA) and Maleic anhydride (MA) were purchased from Central drug house (P) Ltd and Propylene glycol (PG) was purchased from Rankemand was used without further purification in the synthesis of UPRs. Styrene $98 \%$ was purchased from Avra synthesis Pvt. Ltd, Hyderabad, India. Methyl ethyl ketone peroxide (MEKP) and cobaltoctoate were used as received from Lilha\& company, Varanasi, India.

\section{Oil Extraction}

Soxhlet extractor was used to extract oil from the crushed seeds with hexane as a solvent. Hexane was then removed by distillation.

\section{Determination of Physicochemical Properties}

An idea can be obtained about quantity, type of glycerides and mean weight of acid through the use of saponification value along with the acid value for a given sample of oil. ${ }^{18}$ Iodine value determines the characteristic nature of oil. These values express the degree of unsaturation in oils. ${ }^{19}$ Based on iodine value, oils can be further classified as drying (200-130), semi-drying (130-100) and non-drying (lower than 100). ${ }^{20}$ Various physicochemical properties like acid value, saponification and iodine value of the extracted oil was evaluated as per standard methods. ${ }^{21-23}$

\section{Determination of the Fatty Acid Composition}

Perkin Elmer autosystem XLGC with Turbomass was used for the analysis of the fatty acid methyl esters. Helium was used as a carrier gas and total run time for 35min.MS was scanned from 20 to $620 \mathrm{Da}$. NIST library was used for the identification of esters in fatty acid methyl esters of SHUATS ALSI-2.

\section{Synthesis of UPRs}

The Alcoholysis-polyesterification method was applied to synthesize UPRs. ${ }^{24}$ Table-1 shows the amounts of various ingredients used. The above-mentioned process was carried out in a Dean \& Stark type condenser.

In the first stage, oil was transformed into a monoglyceride by heating with continuous stirring a mixture of oil and PG. Methanol solubility test confirms the formation of monoglyceride, in which resin and 
RASĀYAN J. Chem.

Vol. 13 | No. 3 |1834-1841| July - September | 2020

methanol are mixed in a ratio of 1:3 at ambient temperature. The resin completely solubilized in methanol indicated the formation of monoglyceride. ${ }^{25}$

Table-1: Composition of the Synthesized Resin

\begin{tabular}{l|l|l|l|l}
\hline Oil & PG & AA & MA & PA \\
\hline $0.05 \mathrm{M}$ & $0.24 \mathrm{M}$ & $0.10 \mathrm{M}$ & $0.28 \mathrm{M}$ & $0.11 \mathrm{M}$ \\
\hline
\end{tabular}

In the second stage finely divided form of AA and acid anhydride (PA and MA) was added after cooling the reaction mixture. The mixture was again heated continuously until a minimum constant acid value was attained.

Styrene (35 wt $\%$ ) was dissolved in the synthesized resin. To cure the resin, MEKP (2wt\%) and cobaltoctoate $(0.2 \mathrm{wt} \%)$ were added as initiator and accelerator respectively with continuous. ${ }^{3}$

\section{Characterization and Evaluation of Synthesized UPRs}

Fourier Transform Infrared Spectroscopy (FTIR)

FT-IR spectra of the resin were recorded on Perkin Elmer spectrum RX-I. The absorption peaks in between $4000 \mathrm{~cm}^{-1}$ to $400 \mathrm{~cm}^{-1}$ were studied.

Nuclear Magnetic Resonance Spectroscopy $\left({ }^{1} \mathrm{H}\right)$

$\mathrm{H}^{1}$ - NMR spectra of the synthesized polymer samples were scanned on a Bruker Avance II spectrometer working at $400 \mathrm{MHz}$ at $293 \mathrm{~K}$ in $\mathrm{CDCl}_{3}$. Chemical shifts $(\delta)$ were expressed in ppm.

\section{Thermogravimetric Analysis (TGA)}

Thermogravimetric analysis (TGA) was carried out with an EXSTAR TG/DTA 6300. Alumina crucible was used to place samples $(10 \pm 0.2 \mathrm{mg})$. An empty alumina crucible was used as a reference. All materials were heated from $35^{\circ} \mathrm{C}$ to $1000^{\circ} \mathrm{C}$ in a $200 \mathrm{ml} / \mathrm{min}$ flow of air at a heating rate of $10^{\circ} \mathrm{C} / \mathrm{min}$. Continuous recording of sample temperature, weight and heat flow were performed.

\section{Statistic heat-resistant index (Ts)}

The statistic heat resistant index temperature (Ts) was calculated by equation $1 .{ }^{26,27,28}$ values of $\mathrm{T}_{\mathrm{d} 5} \& \mathrm{~T}_{\mathrm{d} 30}$ from the TGA data are used to calculate Ts.

$$
\mathrm{Ts}=0.49\left[\mathrm{~T}_{\mathrm{d} 5}+0.6 \times\left(\mathrm{T}_{\mathrm{d} 30}-\mathrm{T}_{\mathrm{d} 5}\right)\right]
$$

Integral Procedural Decomposition Temperature (IPDT)

Doyle's method as proposed earlier ${ }^{28,29,30}$ was used to calculate the IPDT.

$$
\begin{array}{r}
\operatorname{IPDT}\left({ }^{0} \mathrm{C}\right)=A K *\left(\mathrm{~T}_{\mathrm{f}}-\mathrm{T}_{\mathrm{i}}\right)+\mathrm{T}_{\mathrm{i}} \\
\mathrm{A}=\frac{\mathrm{S}_{1}+\mathrm{S}_{2}}{\mathrm{~S}_{1}+\mathrm{S}_{2}+\mathrm{S}_{3}} \quad \mathrm{~K}=\frac{\mathrm{S}_{1}+\mathrm{S}_{2}}{\mathrm{~S}_{1}}
\end{array}
$$

Where,
A- Area ratio of total experimental curve divided by total TGA thermogram
$\mathrm{T}_{\mathrm{i}^{-}}$- Initial temperature $\left(500^{\circ} \mathrm{C}\right)$
$\mathrm{T}_{\mathrm{f}}$ - Final temperature $\left(800^{\circ} \mathrm{C}\right)$
$S_{1} S_{2} \& S_{3}$ values were determined by earlier studies
$\mathrm{K}$ is the coefficient of $\mathrm{A}$

\section{Physicochemical Properties of Oil}

\section{RESULTS AND DISCUSSION}

The physicochemical properties of the oil are depicted in Table-2. Oil with higher iodine value can be called a drying oil as it signifies the presence of unsaturation; applications in the areas like paints, surface coating production thus become possible because a higher iodine value (177) renders drying capability to the thin film of oil to produce a hard film through auto-oxidation. The saponification value of 204 is 
RASĀYAN J. Chem.

Vol. 13 | No. 3 |1834-1841| July - September | 2020

indicative of its applicability for soap production. The physical and chemical properties are in close approximation to the data provided by other researchers. ${ }^{31}$

Table-2: Physicochemical Properties of Oil

\begin{tabular}{c|c}
\hline Physiochemical Properties & Mean Value \\
\hline Acid Value $(\mathrm{mg} \mathrm{KOH} / \mathrm{g}$ of oil $)$ & 1.5 \\
\hline Saponification Value $(\mathrm{mg} \mathrm{KOH} / \mathrm{g}$ of oil $)$ & 204 \\
\hline Iodine Value $\left(\mathrm{g} \mathrm{I}_{2} / 100 \mathrm{~g}\right.$ of oil $)$ & 177 \\
\hline
\end{tabular}

\section{Fatty Acid Composition}

Table-3 represents the fatty acid composition of the seed oil. The fatty acid profile confirms that the major acid is linolenic acid (49.97\%) accompanied by other components viz. oleic acid (26.38\%), linoleic acid $(13 \%)$, palmitic acid $(5.72 \%)$ and stearic acid $(4.03 \%)$. SHUATS ALSI-2 consists of $9.75 \%$ of saturated and $89.35 \%$ of unsaturated fatty acids.

Table-3: Fatty Acid Composition of the Seed Oil

\begin{tabular}{c|c|c}
\hline Fatty Acids & Retention Time & Percentage $(\%)$ \\
\hline Palmitic acid & 14.49 & 5.72 \\
\hline Stearic acid & 18.25 & 4.03 \\
\hline Oleic acid & 18.57 & 26.38 \\
\hline Linoleic acid & 19.47 & 13.00 \\
\hline Linolenic acid & 21.05 & 49.97 \\
\hline Unknown fatty acids & & 0.90 \\
\hline
\end{tabular}

\section{Synthesis of UPRs}

Transesterification reaction occurs when Linseed oil (SHUATS ALSI-2) is heated with propylene glycol and yields a mixture of products referred to as monoglyceride. The mixture contains monoglyceride, diglyceride, triglyceride and propylene glycol. ${ }^{32}$

The mixture further undergoes polyesterification reaction on the addition of MA and PA and produces unsaturated polyester resin. The polyesterification reaction can be checked and was done by evaluating the acid value at a distinct interval of time.

With the progression of the polyesterification reaction, there was a decrease in acid value. The decrement in acid value was found to be fast in the initial phases of the reaction in comparison to the later phases. This alteration in the change in acid value during thisreaction is supported by the theory of difference in reactivity of primary hydroxyl group and the secondary hydroxyl group of propylene glycol ${ }^{33}$, the former group being more reactive than the latter. It is assumed that the fast decrement in acid value during initial phases is due to reaction of the primary hydroxyl group and the slower decrease in acid value during later stage corresponds to the reaction of secondary hydroxyl group. ${ }^{34}$

The duration when the decrement in acid value is slow, which is contributed by the reaction of the secondary hydroxyl group of propylene glycol, supposedly specify the start of the development of threedimensional networks as a result of cross-linking of polyester chain. ${ }^{35}$

The crosslinking of the alkyd chain causes an increase in the viscosity of the reaction medium. Furthermore, the rate of reactionreduces towards the final stages of reaction due to a decrease in free acids. ${ }^{35}$

\section{Fourier Transform Infrared Spectroscopy (FTIR)}

Existence of major linkages such as olefinic double bonds, ester groups and other specific peaks are indicated by the FT-IR spectra of the developed resin. FT-IR analysis confirms the polyesterification reaction. Figure-1 shows the FTIR spectra of the synthesized resin. The presence of -OH group is confirmed by the broad singlet peak at $3444 \mathrm{~cm}^{-1}$. Aromatic C-H stretching as well as olefinic $\mathrm{C}-\mathrm{H}$ stretching is confirmed by the peak at $3082.2 \mathrm{~cm}^{-1}$. Peaks around $2855.9-2927.7 \mathrm{~cm}^{-1}$ represent aliphatic C$\mathrm{H}$ stretching vibrations. The presence of ester linkages $(\mathrm{C}=\mathrm{O})$ is confirmed by the characteristic peak at $1731.2 \mathrm{~cm}^{-1}$. Peaks around $1601.9-1580 \mathrm{~cm}^{-1}$ confirm the presence of aromatic $\mathrm{C}=\mathrm{C}$. Stretching (-C-O-C-) is confirmed by the peaks around $1261.3-1074.9 \mathrm{~cm}^{-1}$.C-O stretching frequency of ester is confirmed by 
RASĀYAN J. Chem.

Vol. 13 | No. 3 |1834-1841| July - September | 2020

the peak at $1165 \mathrm{~cm}^{-1}$. The peak at $983.4 \mathrm{~cm}^{-1}$ confirms C-C stretching frequency. Peaks around $744.2-$ $700.7 \mathrm{~cm}^{-1}$ correspond out of plane aromatic $\mathrm{C}$-H bending vibration. ${ }^{14,37,38}$

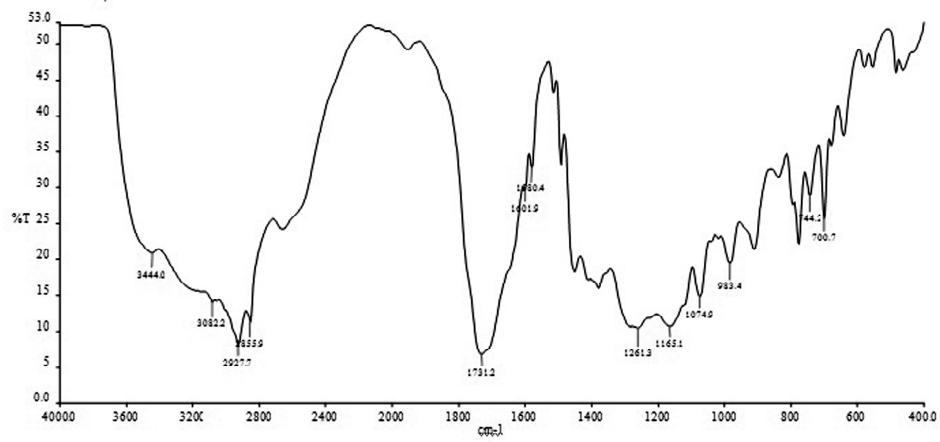

Fig.-1: FTIR Spectra of the Synthesized Resin

\section{Nuclear Magnetic Resonance Spectroscopy $\left({ }^{1} \mathrm{H}\right)$}

Figure-2 depicts the ${ }^{1} \mathrm{H}$ NMR spectra of the synthesized resin. The peak at 1.01 ppmis for the $\mathrm{H}^{1}$ of the terminal $\mathrm{CH}_{3}$ group of the fatty acid chains. The peak at 1.76-1.78 ppm corresponds to the $\mathrm{H}^{1}$ of $\mathrm{CH}_{2}$ groups attached beside to above terminal $\mathrm{CH}_{3}$ group. The peak at 1.31-1.35 ppmis mentioned for all the internal $\mathrm{CH}_{2}$ groups available in the fatty acids chains.

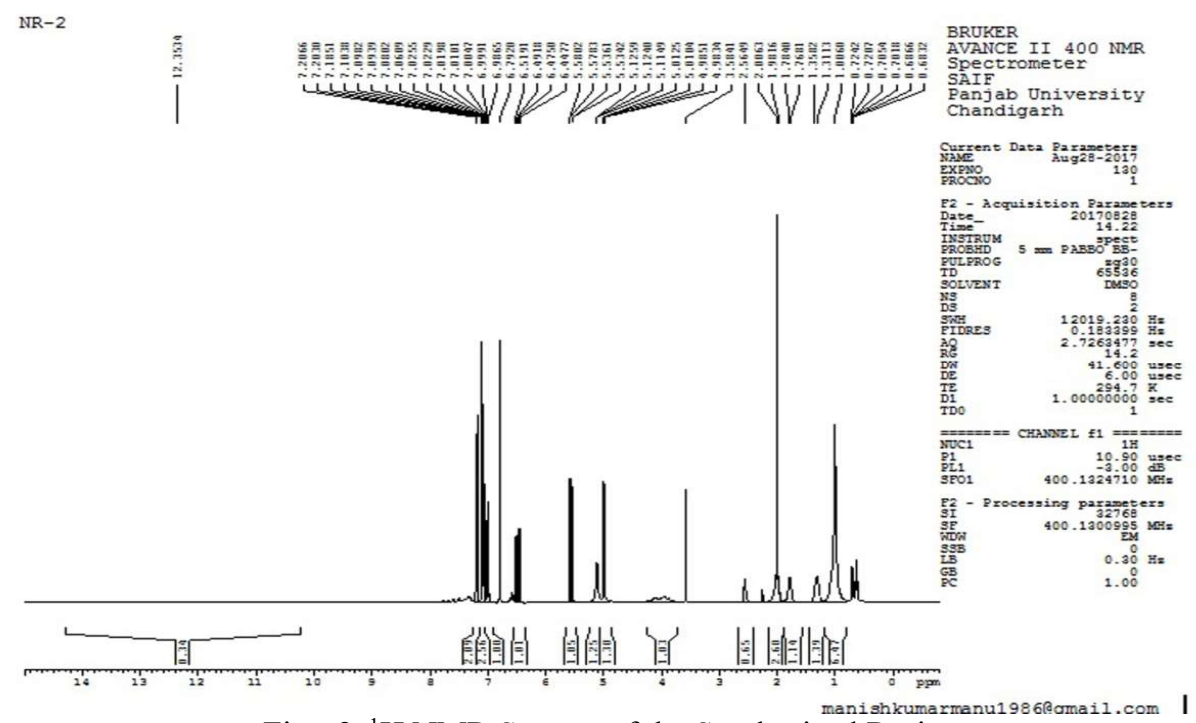

Fig.- 2: ${ }^{1} \mathrm{H}$ NMR Spectra of the Synthesized Resin

The characteristic peak at 5.1-5.5 ppm is for protons of unsaturated carbon. For methylene protons of propylene, glycol moiety is observed at $3.58 \mathrm{ppm}$. The characteristic peaks at $6.98-6.99 \mathrm{ppm}$ are for the protons for $\mathrm{CH}$ of propylene glycol moiety. The peaks at 7.10-7.20 ppm are observed for aromatic protons of phthalic anhydride. ${ }^{14,37,38}$

\section{Thermogravimetric Analysis (TGA)}

Thermo-oxidative stability is a key determining factor in the applicational aspects of UPRs. ${ }^{39}$ Thermal stability of the cured unsaturated polyester resin has been measured in an air atmosphere by thermogravimetric analysis at the heating rate of $10^{\circ} \mathrm{C} / \mathrm{min}$. Figure-3 represents the TGA curve of the commercial resin (CR-1) and synthesized resin (CR-2).

Cured polyester resin usually shows two main temperature ranges for weight loss. Low molecular weight oligomeric component degraded in the range of $100-250^{\circ} \mathrm{C}$ whereas ester linkages and the oil degrades around $250-450^{\circ} \mathrm{C} ., 40,41$ Thermal degradation temperatures of the resin are tabulated in Table- 4 . 
RASĀYAN J. Chem.

Vol. 13 | No. 3 |1834-1841| July - September | 2020

The onset thermal degradation temperature ( $\mathrm{T}_{\text {onset }}$ ) of CR-1 is around $97.4^{\circ} \mathrm{C}$ whereas for $\mathrm{CR}-2$ it is at $136^{\circ} \mathrm{C}$ which may be due to loss of water and other volatile substances. ${ }^{42}$ The earlier degradation of CR-1 can be explained by the assumption that the solvent used is more volatile than the one used for CR-2. ${ }^{43}$

The temperature of $5 \%$ weight loss $\left(\mathrm{T}_{\mathrm{d} 5}\right)$ is at $180.5^{\circ} \mathrm{C}$ for CR-1 and $207^{\circ} \mathrm{C}$ for CR-2. $30 \%$ weight loss $\left(\mathrm{T}_{\mathrm{d} 30}\right)$ temperatures are almost comparable for both CR-1 and CR-2 i.e $354.4^{\circ} \mathrm{C}$ and $345^{\circ} \mathrm{C}$ respectively which correspond to degradation of ester linkages.

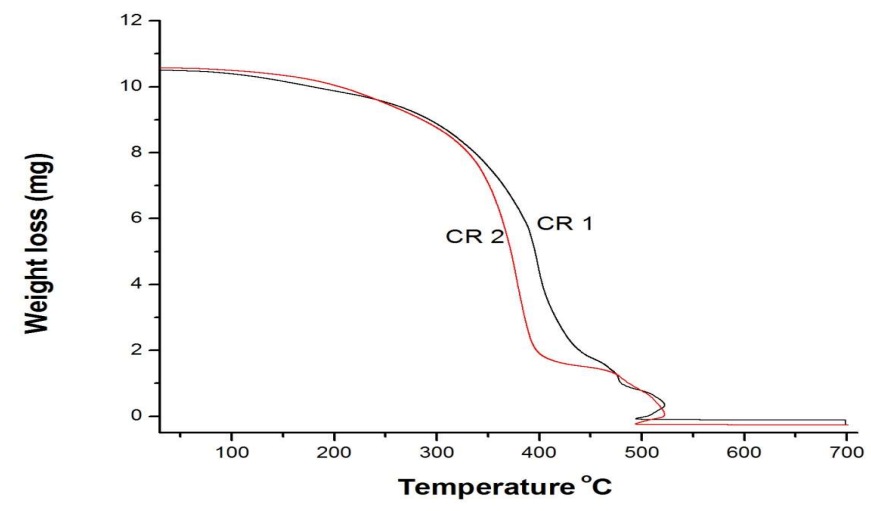

Fig.-3: TGA Curve of the Commercial Resin (CR-1) and Synthesized Resin (CR-2)

Table-4: Thermal Stability Data of CR-1 and CR-2

\begin{tabular}{c|c|c|c}
\hline Sample Code & $\mathrm{T}_{\text {onset }}{ }^{\circ} \mathrm{C}$ & $\mathrm{T}_{\mathrm{d} 5}{ }^{\circ} \mathrm{C}$ & $\mathrm{T}_{\mathrm{d} 30}{ }^{\circ} \mathrm{C}$ \\
\hline $\mathrm{CR}-1$ & 97.4 & 180.5 & 354.4 \\
\hline $\mathrm{CR}-2$ & 136 & 207 & 345 \\
\hline
\end{tabular}

Where, $\mathrm{T}_{\text {onset- }}$ Onset Temperature, $\mathrm{T}_{\mathrm{d} 5}$ - Temperature of $5 \%$ weight loss

$\mathrm{T}_{\mathrm{d} 30}$ - Temperature of $30 \%$ weight loss, $\mathrm{T}_{\mathrm{s}}$-Statistic heat resistant index temperature

The Ts and IPDT are specific parameters to explain the thermal stability of the cured resins. ${ }^{28}$ Parameters of thermal stability of cured resins are shown in Table-5.

Table-5: Parameters of Thermal Stability of Cured Resins

\begin{tabular}{c|c|c}
\hline Sample Code & IPDT $\left({ }^{\circ} \mathrm{C}\right)$ & Ts $\left({ }^{\circ} \mathrm{C}\right)$ \\
\hline CR-1 & 525 & 140 \\
\hline CR-2 & 494 & 142 \\
\hline
\end{tabular}

The value of Ts of CR-2 is $142^{\circ} \mathrm{C}$ which is at par with CR-1 i.e $140^{\circ} \mathrm{C}$ whereas IPDT for CR-1 is at $525^{\circ} \mathrm{C}$ and $494^{\circ} \mathrm{C}$ for CR-2. These data indicate that CR-2 is thermally more stable than CR-1.

\section{CONCLUSION}

Unsaturated polyester resin (UPRs) based on a new linseed variety (SHUATS-ALSI 2) and a mixture of PA, MA, PG and AA in varying amounts by a two-stage alcoholysis-polyesterification process have been successfully synthesized. The FTIR and $\mathrm{H}^{1}$-NMR spectra confirmed the structure of the resin and TGA studies along with the values of IPDT and Ts confirms its thermal stability. On comparison, it is being found that the values of $T_{\text {onset }}$ and $T_{d 5}$ for synthesized resin (CR-2) is higher than the commercial resin (CR-1) while the $\mathrm{T}_{\mathrm{d} 30}$ value of the CR-2 is higher than the CR-1. Even the values of IPDT and Ts are almost comparable for both resins. Based on these results, it can be concluded that UPRs based on new linseed variety SHUATS-ALSI 2 is thermally stable and has tremendous potential to be a good alternative for fossil fuel-based polymers.

\section{REFERENCES}

1. K. G. Johnson and L. S. Yang, Modern Polyester: Chemistry and Technology of Polyesters and Copolyesters, John Wiley \& Sons Ltd., p.699-713(2003).

2. M. Biron, Thermoset and Composites, Elsevier Ltd, New York (2004). 
RASĀYAN J. Chem.

Vol. 13 | No. 3 |1834-1841| July - September | 2020

3. C.S.M.F. Costa, A.C. Fonseca, J. Moniz, M. Godinho, A.C. Serra and J.F.J. Coelho, Industrial Crops and Products, 85, 403(2016), DOI: 10.1016/j.indcrop.2016.01.030

4. C. K.Williams and M.A. Hillmyer, Journal of Polymer Reviews, 48(1), 1(2008).

5. A. Chowdhury and P. Anthony, International Journal of Science and Research,5(2), 1786(2016).

6. Y. Xia and R.C. Larock, Green Chemistry, 12(11), 1893(2010), DOI:10.1039/C0GC00264J

7. Y. Xu, Z. S. Petrovic, S. Das and G. Wlilkes, Polymers, 49(19),4248(2008), DOI:10.1016/j.polymer.2008.07.027

8. S. K. Sahoo, V. Khandelwal and G. Manik, Polymer Advanced Technologies, 29(7), 1(2018), DOI: $10.1002 /$ pat. 4316

9. D.I. Caglar, E. Bastürk, B. Oktay and M. V. Kahraman, Progress in Organic Coatings, 77, 81(2014), DOI: $10.1016 /$ j.porgcoat.2013.08.005

10. T. T. Ngo, C. A. Lambert and J.G. Kohl, Polymer-Plastics Technology and Engineering, 53, 1215(2014), DOI: 10.1080/03602559.2014.886121.

11. S. Jayavani, S. Sunanda, T. O. Vargheseand, S. K. Nayak, Journal of Cleaner Production, 162,795(2017), DOI:10.1016/j.jclepro.2017.06.040

12. M. Gobin, P. Loulergue, J. L. Audic and L. Lemiègre, Industrial Crops and Products,70, 213(2015), DOI: $10.1016 /$ j.indcrop.2015.03.041

13. M. M. Bora, R. Deka, N. Ahmed and D.K. Kakati, Industrial Crops and Products, 61, 106(2014), DOI: $10.1016 /$ j.indcrop.2014.06.048

14. M.M. Bora, P. Gogoi, D.C. Deka and D.K Kakati, Industrial Crops and Products, 52, 721(2014), DOI: 10.1016/j.indcrop.2013.11.012

15. M. Boruah, P. Gogoi, B. Adhikari and S. K. Dolui, Progress in Organic Coating, 74(3), 596(2012), DOI: $10.1016 /$ j.porgcoat.2012.02.007

16. N. Dutta, N. Karak and S. K. Dolui, Progress in Organic Coating, 49(2),146(2004), DOI: $10.1016 /$ j.porgcoat.2003.09.005

17. Proceedings of 57 Meeting of State Seed Varietal Release Sub-committee, (2018).

18. W. Odoom and V. O. Edusei, Asian Journal of Agriculture and Food Science,3(5), 494(2015).

19. Y. Pomeranz and C. E. Meloan, Food Analysis: Theory and Practice, $2^{\text {nd }}$ ed., Van Nostrand Reinhold Company, New York, p. 81-765 (1987).

20. H. J. Duel, Tr., The lipids: their Chemistry and Biochemistry, Vol.1, New York, Inter Science Publishers, p. 53-57 (1951).

21. AACC International Method 58-15.01, 1999a, Determination of Free Fatty Acids

22. AACC International Method 58-50.01, 1999b, Saponification Value.

23. ASTM, 1959. Test for Iodine Value of Drying Oils and Fatty Acids, Part 20, 1973, 748.

24. D. Stoye, Alkyd Resins, In: Stoye, D., Freitag, W., (Eds.), Resins for Coatings: Chemistry, Properties and Applications. Carl Hanser Verlag, Munich, p.1-28 (1996).

25. R.H. Runk, Industrial and Engineering Chemistry, 44, 1124(1952), DOI:10.1021/ie50509a054

26. R. S. Lehrle and R. J. Williams, Macromolecules, 27(14), 3782(1994), DOI:10.1021/ma00092a017

27. B. Jiang, J. Hao, W. Wang, L. Jiang and X. Cai, European Polymer Journal,37(3), 463(2001), DOI: $10.1016 / \mathrm{S} 0014-3057(00) 00147-6$

28. Y. C. Chiu, I. C. Chou, W. C. Tseng and C.C.M. Ma, Polymer Degradation and Stability, 93, 668(2008), DOI:10.1016/j.polymdegradstab.2007.12.014

29. C. D. Doyle, Analytical Chemistry, 33(1), 77(1961), DOI:10.1021/ac60169a022

30. S. J. Park and M. S. Cho, Journal of Materials Science, 35(14), 3525(2000), DOI: $10.1023 / \mathrm{A}: 1004849110311$

31. V. M. Popa, A. Gruia, D. N. Raba, D. Dumbrava, C. Moldovan, D. Bordean and C. Mateescu, Journal of Agroalimentary Processes and Technologies, 18 (2), 136(2012).

32. I. O. Igwe and O. Ogbobe, Journal of Applied Polymer Science, 78, 1826(2000), DOI:10.1002/10974628(20001205)78:10<1826::AID-APP150>3.0.CO;2-P

33. H. A. Goldsmith, Industrial and Engineering Chemistry, 40, 1205(1948), DOI:10.1021/ie50463a009

34. A. I. Aigbodion and F. E. Okieimen, Industrial Crops and Products, 13, 29(2001), DOI:10.1016/S0926-6690(00)00050-9 
RASĀYAN J. Chem.

Vol. 13 | No. 3 |1834-1841| July - September | 2020

35. A. I. Aigbodion and F. E. Okieimen, European Polymer Journal, 32(9), 1105(1996), DOI: 10.1016/0014-3057(96)00053-5

36. D. S. Ogunniyi and T. E. Odetoye, Bioresource Technology, 99, 1300(2008), DOI: 10.1016/j.biortech.2007.02.044

37. P. P. Chiplunkar and A. P. Pratap, Progress in Organic Coating, 93, 61(2016), DOI: $10.1016 /$ j.porgcoat.2016.01.002

38. D. I. Caglar, E. Bastürk, B. Oktay and M.V. Kahraman, Progress in Organic Coating ,77(1), 81(2014), DOI:10.1016/j.porgcoat.2013.08.005

39. H. Nosal, J. Nowicki, M. Warzała, I. Semeniuk and E. Sabura, Progress in Organic Coating,101, 553(2016), DOI:10.1016/j.porgcoat.2016.10.003

40. F.A.M.M. Gonçalves, C.S.M.F Costa., I. G. P. Fabela, D. Farinha, H. Faneca, P. N. Simões, A. C. Serra, P. J. Bártolo and J.F.J.Coelho, Biofabrication, 6(3), 035024 (2014).

41. S. Grishchuk, R. Leanza, P. Kirchner, J. Karger-Kocsis, Journal of Reinforced Plastics Composites, 30(17), 1455(2011).

42. J. Giri, R. Lach, J. Sapkota, A.B.H.Susan, J.M. Saiter, S.Henning, V. Katiyar and R. Adhikari, Bibechana, 16, 177(2019).

43. H. Nosal, J. Nowicki, M. Warzała, E. Nowakowska-Bogdan and M. Zar ebska, Progress in Organic Coating, 86, 59(2015), DOI:10.1016/j.porgcoat.2015.04.009

[RJC-5875/2020] 